Gut, 1986, 27, 324-328

\title{
Anticomplement receptor activity in the serum of patients with primary biliary cirrhosis
}

\author{
G Y MINUK, J VERGALlA, R G HANSON, J H HOOFNAGLE, M M FRANK, \\ AND E A JONES \\ From the Liver Diseases Section, Digestive Diseases Branch, National Institute of Arthritis, Diabetes, and \\ Digestive and Kidney Diseases and the Laboratory of Clinical Investigation, National Institute of Allergy and \\ Infectious Diseases, National Institutes of Health, Bethesda, Maryland, USA
}

SUMMARY Patients with primary biliary cirrhosis have a defect in the receptor mediated clearance of complement coated erythrocytes by fixed macrophages of the reticuloendothelial system. To investigate the probable mechanism of this defect peripheral blood monocytes were isolated from nine patients with primary biliary cirrhosis and seven control subjects and the ability of these cells to form rosettes with complement coated, IgM-sensitised sheep erythrocytes was assessed. Primary biliary cirrhosis peripheral blood monocytes formed rosettes to the same extent as control peripheral blood monocytes $(71 \cdot 0 \pm 7 \cdot 1 \%$ [SEM] versus $73 \cdot 3 \pm 4 \cdot 3 \%$ ) suggesting normal complement receptor function of primary biliary cirrhosis peripheral blood monocytes. When primary biliary cirrhosis or control peripheral blood monocytes were preincubated with primary biliary cirrhosis serum, however, the per cent of peripheral blood monocytes that formed rosettes was decreased: $2 \cdot 4 \pm 0.8$ and $3 \cdot 1 \pm 1 \cdot 3$ fold respectively. To study this phenomenon further, fractions containing IgG or IgM synthesised by cultures of control or primary biliary cirrhosis lymphocytes were prepared. Rosette formation was not affected by exposure to fractions containing control or primary biliary cirrhosis IgG or control IgM, but was markedly inhibited $(6 \cdot 0 \pm 4 \cdot 8$ fold $)$ by exposure to fractions containing primary biliary cirrhosis IgM. Similar results were obtained when freshly isolated peripheral blood monocytes or peripheral blood monocytes that had been cultured for 7-10 days - that is, macrophages, were used. Assuming that one can draw inferences concerning the status of fixed macrophages from data obtained using peripheral blood monocytes, the results of this study suggest that the complement specific defect in reticuloendothelial system clearance function in primary biliary cirrhosis is not caused by an abnormality in the functional status of complement receptors on fixed macrophages but rather by a factor present in the serum of patients with primary biliary cirrhosis that has the capacity to inhibit the adherence of complement coated erythrocytes to complement receptors present on the surface of fixed macrophages. This serum factor does not appear to be a complement component but rather a product of peripheral blood mononuclear cells, other than IgG.

One of the numerous and intriguing abnormalities of immune function that has been reported in patients with primary biliary cirrhosis ${ }^{1}$ is a defect in the clearance of complement opsonised erythrocytes by complement receptors on fixed macrophages of

Address for correspondence: Dr Gerald Y Minuk, Department of Medicine, Health Sciences Centre, The University of Calgary, Calgary, Alberta T2N 4N1, Canada.

Received for publication 26 April 1985 the reticuloendothelial system. ${ }^{2}$ This defect can be shown by following the fate of intravenously administered IgM-sensitised radiochromated autologous erythrocytes. Such erythrocytes become opsonised with complement, particularly $\mathrm{C} 3$, as a consequence of local activation of the classical complement pathway. ${ }^{3}$ These complement coated cells are then cleared from the circulation by the reticuloendothelial system. The cause of the defect 
in the clearance of complement coated cells in primary biliary cirrhosis has not been determined. It does not appear to be attributable to a decrease in hepatic blood flow, a deficiency in the number or phagocytic function of Kupffer cells or inadequate serum concentrations of components of the classical complement pathway. ${ }^{45}$ Two possible explanations that have not yet been excluded are (i) an abnormality in the number or affinity of receptors for complement on fixed macrophages and (ii) the presence in serum of a factor that inhibits receptormediated uptake of complement coated particles by fixed macrophages. This study was designed to address both of these possibilities.

\section{Methods}

\section{SUBJECTS}

Nine patients with primary biliary cirrhosis and seven controls (three normal volunteers and four patients with non-primary biliary cirrhosis chronic liver diseases) were studied. The diagnosis of primary biliary cirrhosis was based on the presence of typical clinical, serum biochemical, serological, hepatic histologic and, where appropriate, cholangiographic findings. Eight of the nine primary biliary cirrhosis patients, and two of the seven controls had raised concentrations of immune complex-like material in their serum - that is, material that gave a positive reaction in the Raji cell radioimmunoassay and/or the $\mathrm{C1q}$ binding assay). Serum IgM concentrations were raised in six of the nine primary biliary cirrhosis patients but in none of the seven controls. All four histologic stages of primary biliary cirrhosis defined by Scheuer were represented in the patients studied. ${ }^{6}$

Human peripheral blood mononuclear cells were isolated from blood by centrifugation on FicollHypaque. ${ }^{7}$ Monolayers were prepared by allowing peripheral blood monocytes to adhere to glass tissue culture chambers (Miles Laboratories, Inc, Naperville) and then gently washing the chambers. The viability of peripheral blood mononuclear cells and peripheral blood monocytes, as assessed by the exclusion of Trypan Blue dye was $>90 \%$. Peripheral blood monocytes were used in experiments either immediately after isolation or after culture for seven to 10 days. The cultured monocytes resembled macrophages morphologically. ${ }^{8}$

Sheep red blood cells were sensitised by incubating equal volumes of a $5 \%(\mathrm{v} / \mathrm{v})$ suspension of sheep red blood cells and a 1:60 dilution of rabbit 19S (IgM) antibody to sheep red blood cells (Cordis Laboratories, Miami) in phosphate buffered saline for 30 minutes at $37^{\circ} \mathrm{C}$. Equal volumes of a $5 \%(\mathrm{v} / \mathrm{v})$ suspension of sensitised sheep red blood cells (EA) and a 1:10 dilution of pooled $\mathrm{Balb} / \mathrm{C}$ mouse sera were subsequently incubated on a rocking platform for 45 minutes at $37^{\circ} \mathrm{C}$ to generate complement coated sheep erythrocytes (EAC).

Serum was obtained from fresh plasma by the addition of $\mathrm{CaCl}_{2}$ (final concentration $20 \mathrm{nM}$ ). The serum (free of fibrin-clot) was then suspended (5\% $\mathrm{v} / \mathrm{v}$ ) in RPMI-HEPES buffer containing L-glutamine $(4 \mathrm{mmol})$, penicillin $(10000 \mathrm{U} / \mathrm{ml})$ and streptomycin (10 $000 \mu \mathrm{g} / \mathrm{ml})$ (Grand Island Biological Company, Grand Island, NY). In addition, to generate fractions containing immunoglobulin free of antigen, supernatants were harvested from 10 day old cultures of pokeweed mitogen stimulated peripheral blood mononuclear cells from four individuals (three primary biliary cirrhosis and one control). ${ }^{9}$ The supernatants were concentrated by ultrafiltration and passed through a staphylococcal protein $\mathrm{A}$ Sepharose-CL-4B affinity column (Pharmacia, Uppsala, Sweden), which preferentially binds IgG1, IgG2, and IgG4. IgG-enriched fractions were eluted with $1 \mathrm{~mol}$ acetic acid directly into tubes containing concentrated buffer. Both the non-adherent IgMcontaining fractions and the adherent IgG-enriched fractions were also concentrated by ultrafiltration and dialysed against buffer. The concentrations of IgM and IgG in the concentrated fractions were similar to those in the plasma of the subject from whom the peripheral blood mononuclear cells had been isolated.

To each chamber containing a monolayer of peripheral blood monocytes, $250 \mu \mathrm{l}$ of a suspension of serum or an immunoglobulin containing fraction was added. The chambers were incubated for one hour at $37^{\circ} \mathrm{C}$ in a humidified atmosphere before being washed extensively with Hanks Balanced Salt solution. After the addition of complement coated sheep erythrocyte indicator cells $\left(250 \mu \mathrm{l}, 1 \times 10^{8}\right.$ $\mathrm{EAC} / \mathrm{ml}$ ) the chambers were incubated again for one hour at $37^{\circ} \mathrm{C}$. Non-adherent complement coated sheep erythrocytes were removed by gentle washes with Hanks Balanced Salt solution. The cells remaining in the chambers were fixed in $0.5 \%$ glutaraldehyde (Sigma Chemical Co, St Louis, MO) and stained with a $2 \%$ Giemsa stain (Hareleco, Gibbstown, NJ). Each set of incubations included two control chambers in which erythrocytes alone were added to the peripheral blood monocyte monolayers. All assays were done in duplicate and interpreted under code. For the purpose of this study the adherence and/or internalisation of three or more complement coated sheep erythrocytes by a peripheral blood monocytes was regarded as a rosette. At least 100 peripheral blood monocytes per chamber were assessed for the presence or absence of rosette formation. 
Results

FUNCTION OF COMPLEMENT RECEPTORS ON

MONOCYTES IN PRIMARY BILIARY CIRRHOSIS

Data on complement receptor function are shown in

Figure 1. Any effect of primary biliary cirrhosis serum on the function of complement receptors was minimised by washing cells extensively and preincubating them in a control serum mixture. The results indicate that primary biliary cirrhosis and control have a similar capacity to form peripheral blood monocytes complement coated sheep erythrocyte rosettes $(71 \cdot 0 \pm 7 \cdot 1 \%$ versus $73 \cdot 3 \pm 4 \cdot 3 \%$, mean \pm SEM). Similar results were obtained when peripheral blood monocytes that had been cultured for 10 days (macrophages) were used.

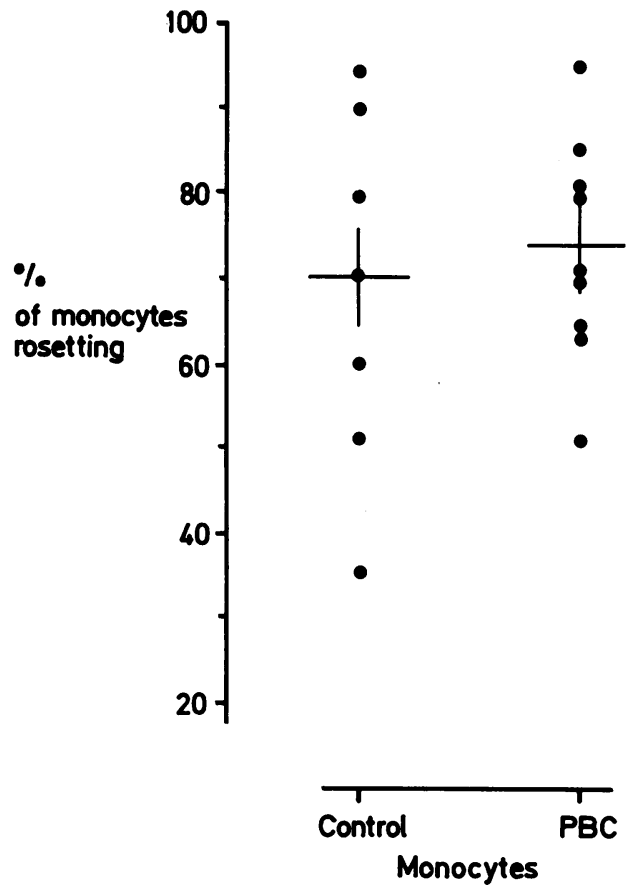

Fig. 1 Assessment of complement receptor function. Peripheral blood monocytes (PBM) from patients with primary biliary cirrhosis $(P B C)$ and control subjects were washed extensively and incubated for 1 hour at $37 \mathrm{C}$ in a $5 \%$ control serum mixture.

Complement-coated sheep erythroyctes (EACs) $(250 \mu \mathrm{l}$ of $1 \times 10^{8} \mathrm{EAC} / \mathrm{ml}$ ) were then incubated with peripheral blood monocyte monolayers for 1 hour at $37^{\circ} \mathrm{C}$. The number of peripheral blood monocytes that formed rosettes was determined and expressed as a per cent of the total peripheral blood monocytes counted. Each dot represents the mean of duplicate determinations. The horizontal bars indicate group means, and the vertical bars the standard errors of the means.
EFFECT OF PRIMARY BILIARY CIRRHOSIS SERUM ON THE FUNCTION OF COMPLEMENT RECEPTORS ON MONOCYTES

Data on the effects of primary biliary cirrhosis serum on the formation of complement coated sheep erythrocyte rosettes by peripheral blood monocytes are shown in Figure 2. In order to minimise the degree of interexperimental variation the results are expressed as a ratio of the per cent of peripheral blood monocytes that formed rosettes after exposure to a heterologous (either control or primary biliary cirrhosis) serum mixture to the per

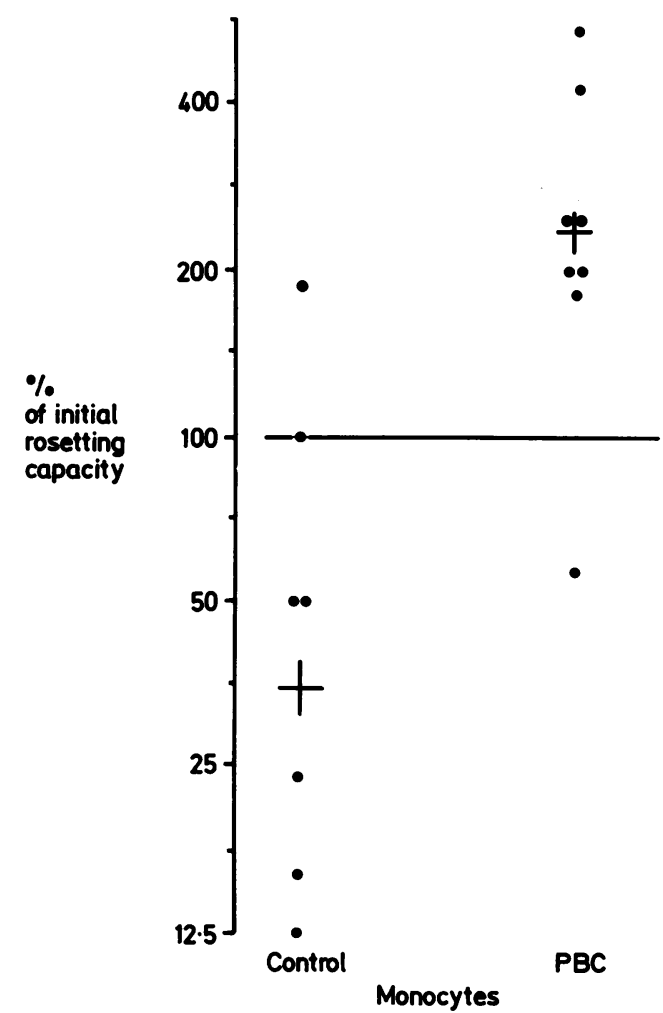

Fig. 2 Effect of serum on EAC rosette formation. The effect of a 5\% heterologous (either primary biliary cirrhosis or control) serum mixture on rosette formation. The proportion of peripheral blood monocytes that formed rosettes after exposure to heterologous sera is expressed as a percentage of the proportion of peripheral blood monocytes that formed rosettes after exposure to an autologous serum mixture. Each dot represents the mean of two or more determinations. Control peripheral blood monocytes were exposed to a primary biliary cirrhosis (PBC) serum mixture and PBC peripheral blood monocytes were exposed to a control serum mixture. The horizontal bars indicate group means, and the vertical bars the standard errors of the means. 
cent of peripheral blood monocytes that concurrently formed rosettes after exposure to an autologous serum mixture. Heterologous serum, in experiments using primary biliary cirrhosis peripheral blood monocytes, consisted of a control serum mixture (from one healthy subject and at least one patient with non-primary biliary cirrhosis chronic liver disease) and in experiments using control peripheral blood monocytes, consisted of a mixture of at least two different primary biliary cirrhosis sera. Rosette formation decreased by a factor $3 \cdot 1 \pm 1 \cdot 3$ when control peripheral blood monocytes were preincubated with primary biliary cirrhosis serum mixtures. In contrast, rosette formation increased by a factor of $2 \cdot 4 \pm 0.8$ when primary biliary cirrhosis peripheral blood monocytes were preincubated with control serum mixtures (Fig. 2). Similar results were obtained when peripheral blood monocytes that had been cultured for 10 days (macrophages) were used.

\section{EFFECTS OF IMMUNOGLOBULIN CONTAINING FRACTIONS ON THE FUNCTION OF COMPLEMENT RECEPTORS ON MONOCYTES}

The effects of various immunoglobulin containing fractions on the formation of rosettes by peripheral blood monocytes were expressed as the ratio of the per cent of control peripheral blood monocytes that formed rosettes after preincubation with a specific immunoglobulin containing fraction to the per cent of control peripheral blood monocytes that formed rosettes after preincubation with a control serum mixture. There was no change in rosette formation by control peripheral blood monocytes after exposure to fractions enriched in control IgG, primary biliary cirrhosis IgG, or control IgM. Fractions enriched in primary biliary cirrhosis IgM, however, markedly inhibited rosette formation by control peripheral blood monocytes $(6 \cdot 0 \pm 4 \cdot 8$ fold, $n=3)$. Similar results were obtained when peripheral blood monocytes that had been cultured for 10 days (macrophages) were used.

\section{Discussion}

Because of the possibility that the complement specific defect of reticuloendothelial system clearance function exhibited by patients with primary biliary cirrhosis could be caused by an abnormality in either the number or affinity of complement receptors on fixed macrophages it was necessary to study the functional status of receptors for complement on reticuloendothelial system cells in the absence of potential inhibitory serum factors. The application of the rosetting assay used in the present study precludes an absolute determination of either the number of surface receptors for complement or the number of IgM antibody molecules per sheep red blood cell. Assuming the status of complement receptors on monocytes and fixed macrophages of the reticuloendothelial system is similar, the values generated for the per cent of peripheral blood monocytes that formed complement coated sheep erythrocyte rosettes suggest that in primary biliary cirrhosis the number and function of complement receptors on the surface of reticuloendothelial system cells are probably adequate to mediate normal C3 receptor-dependent clearance function.

Although subtle abnormalities in the number or affinity of receptors for $\mathrm{C} 3$ on fixed macrophages of the reticuloendothelial system in primary biliary cirrhosis cannot be excluded, the results of the experiments designed to determine the effect of primary biliary cirrhosis serum on complement coated sheep erythrocyte rosette formation suggest that a likely cause of the complement-specific reticuloendothelial system clearance defect in this disease is probably a serum factor that interferes with the recognition of C3-opsonised particles by C3 receptors on fixed macrophages. Serum factors that could potentially mediate such an inhibitory effect include: complement-containing immune complexes ${ }^{10}$ complement-immunoglobulin complexes ${ }^{11}$ excess free conversion products of complement, ${ }^{12}$ anticomplement receptor antibodies, or an immunomodulating factor. The isolation and purification of such factors from serum cannot readily be achieved. Accordingly, it is necessary to apply an alternative experimental approach to determine the probable nature of the inhibitory factor.

In this study the approach adopted was to test fractions containing immunoglobulins synthesised by lymphocytes in a complement and antigen free system for their ability to impair complement coated sheep erythrocyte rosette formation by peripheral blood monocytes. The preliminary results of applying this experimental approach indicate that fractions containing primary biliary cirrhosis IgM, but not those enriched with primary biliary cirrhosis $\mathrm{IgG}$, mediated a marked inhibitory effect on complement coated sheep erythrocyte rosette formation by peripheral blood monocytes and macrophages. The data do not exclude the possibility that this inhibitory affect may be because of non-specific adherence of aggregated IgM to peripheral blood monocytes or indeed to non-IgM inhibitory factors produced by peripheral blood monocytes such as lymphokines. Another possible explanation of the data is that an anticomplement receptor IgM antibody may mediate the complement-specific reticuloendothelial system clearance defect in primary biliary cirrhosis. Antireceptor antibodies have been described in several other diseases presumed to have 
an autoimmune basis. ${ }^{13}$ Moreover, there is evidence which suggests that an anti-Fc receptor antibody may contribute to the raised serum concentrations of immune complexes found in patients with certain autoimmune diseases including systemic lupus erythematosus and rheumatoid arthritis. ${ }^{14}$

A study analogous to the present one has recently been reported by Al-Aghbar and colleagues. ${ }^{15}$ The two studies complement each other and raise issues that should stimulate further research relating to the complement specific reticuloendothelial system clearance defect in primary biliary cirrhosis. Both studies have confirmed that primary biliary cirrhosis serum contains a factor which inhibits the function of $\mathrm{C} 3$ receptors on peripheral blood monocytes. The present study indicates that this finding also applies to receptors on macrophages, whereas that of Al-Aghbar et $a^{15}$ indicates that it also applies to receptors on lymphocytes. The results of both studies suggest that the serum inhibitory activity is not attributable to immune complexes. The findings in the two studies differ in two important respects. Whereas in the present study no defect in the function of $\mathrm{C} 3$ receptors on peripheral blood monocytes from patients with primary biliary cirrhosis was found, the data generated by $\mathrm{Al}$-Aghbar et al $^{15}$ suggested that the number of $\mathrm{C} 3$ receptors on peripheral blood monocytes of patients with primary biliary cirrhosis is reduced. Furthermore, the data in the present study suggest that serum $\mathrm{C} 3$ receptor inhibitory activity in primary biliary cirrhosis is not mediated by a complement component, whereas the findings in the study of Al-Aghbar et al ${ }^{15}$ suggest the opposite conclusion.

In conclusion, the results of this study suggest that a factor present in primary biliary cirrhosis serum rather than an intrinsic defect of receptors on macrophages is responsible for the impaired clearance of complement coated erythrocytes by the reticuloendothelial system which has been found in patients with primary biliary cirrhosis. This serum factor appears to be a product of peripheral blood monocytes, other than IgG.

The results of this study were presented in part at the annual meeting of the American Association for the Study of Liver Diseases, which was held in Chicago, Illinois, in November 1982, and were published in abstract form (Hepatology 1982; 2: 726).

\section{References}

1 James SP, Vierling JM, Strober W. The role of the immune response in the pathogenesis of primary biliary cirrhosis. In: Jones EA, ed. Seminars in liver diseases. Vol 1, no 4. New York: Thieme Stratton, 1981: 322-37.

2 Jaffe CJ, Vierling JM, Jones EA, Lawley TJ, Frank MM. Receptor specific clearance by the reticuloendothelial system in chronic liver diseases: demonstration of defective $\mathrm{C} 3 \mathrm{~b}$ specific clearance in primary biliary cirrhosis. J Clin Invest 1978; 62: 1069-77.

3 Frank MM, Schreiber AD, Atkinson JP, Jaffe CJ. Pathophysiology of immune hemolytic anemia. Ann Intern Med 1977; 87: 210-22.

4 Jones EA, Frank MM, Jaffe CJ, Vierling JM. Primary biliary cirrhosis and the complement system. Ann Intern Med 1979; 90: 72-84.

5 Potter BJ, Trueman AM, Jones EA. Serum complement in chronic liver disease. Gut 1973; 451-6.

6 Scheuer PJ. Biliary disease. In: Liver biopsy interpretation. London: Balliere Tindall, 1980: 36-59.

7 Boyum A. Isolation of mononuclear cells and granulocytes from human blood. Scand J Clin Lab Invest 1968; 21: suppl 97: 77

8 Newman SL, Musson RA, Henson PM. Development of functional complement receptors during in vitro maturation of human monocytes into macrophages. $J$ Immunol 1980; 125: 2236-44.

9 James SP, Elson CO, Jones EA, Strober W. Abnormal regulation of immunoglobulin synthesis in vitro in primary biliary cirrhosis. Gastroenterology 1980; 79: 242-54.

10 Nishi T, Bahn AK, Collins AB, McClusket RT. Effect of circulating immune complexes on $\mathrm{Fc}$ and $\mathrm{C} 3$ receptors of Kupffer cells in vivo. Lab Invest 1981; 44: 442-8.

11 Lindgren S, Eriksson S. IgM in primary biliary cirrhosis. J Lab Clin Med 1982; 99: 636-45.

12 Tiesberg $\mathrm{P}$, Gjone E. Circulating conversion products of $\mathrm{C} 3$ in liver disease. Evidence of in vitro activation of the complement system. Clin Exp Immunol 1973; 14: 509-14.

13 Newsom-Davis J. Receptor antibodies as mediators of autoimmune disorders with particular reference of myasthenia gravis. In: Steffen $\mathrm{C}$, Ludwig $\dot{H}$, eds. Clinical immunology and allergy. New York: Biochemical Press: 1981: 25-32.

14 Falus A, Kavai M, Meretey K, Bozoky S. Autoantibodies specific to $B_{2}$-microglobulin inhibit the $F c$ receptor-dependent phagocytosis of human monocytes. Immune Letters 1981; 3: 45-9.

15 Al-Aghbar MNA, Neuberger J, Williams R, Eddleston ALWF. Mononuclear cell complement receptor blockade in primary biliary cirrhosis. Gut 1985 ; 26: 20-5. 